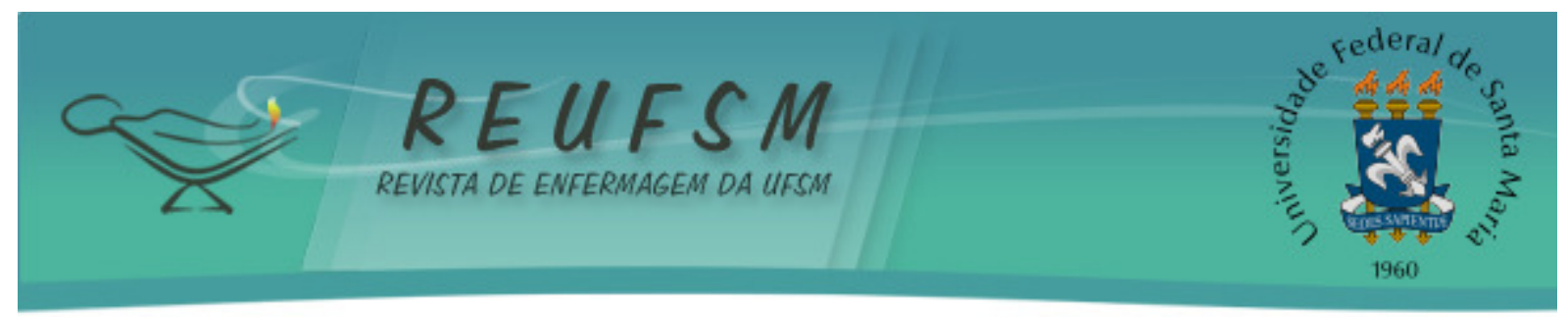

ARTIGO ORIGINAL

\title{
CONTRIBUIÇÕES DA EXTENSÃO UNIVERSITÁRIA NA FORMAÇÃO DE ACADÊMICOS DE ENFERMAGEM
}

\section{CONTRIBUTIONS OF UNIVERSITY EXTENSION ON THE FORMATION OF NURSING ACADEMICS}

\section{CONTRIBUCIÓN DE LA EXTENSIÓN UNIVERSITÁRIA EN LA FORMACIÓN DE ESTUDIANTES DE ENFERMERIA}

\author{
Taísa de Paula Paiva Freitas ${ }^{1}$ \\ Cristiane Cardoso de Paula ${ }^{2}$ \\ Bruna Pase Zanon ${ }^{3}$ \\ Fernando Setembrino Cruz Meirelles ${ }^{4}$ \\ Teresinha Heck Weiller ${ }^{5}$ \\ Stela Maris de Mello Padoin ${ }^{6}$
}

Doi: $10.5902 / 2179769219966$

RESUMO: Objetivo: analisar as contribuições de ações extensionistas na formação de egressos dos projetos de extensão do Programa AIDS, educação e cidadania. Método: estudo transversal com abordagem quantitativa. A população do estudo foi de 43 egressos de projetos de extensão, vinculados ao Curso de Enfermagem de uma Universidade Federal. A coleta de dados se deu por meio de questionário enviado por e-mail durante o período de abril a maio de 2015. Os dados foram analisados pelo programa Predictive Analytics Software. Resultados: Verificou-se a autonomia adquirida pelos acadêmicos após a participação nas atividades extensionistas, tanto no desenvolvimento pessoal, relacionado ao aprendizado, trabalho em equipe e respeito ao outro, como no desenvolvimento acadêmico, em que houve a oportunidade de realizar atividades que não são encontradas na grade curricular. Conclusão: A participação dos acadêmicos em projetos de extensão favorece a responsabilidade de contribuir de maneira decisiva para a transformação social, individual e coletiva.

Descritores: Avaliação educacional; Desenvolvimento de pessoal; Ensino; Estudantes de enfermagem.

ABSTRACT: Aim: to analyze the contributions of extension actions in the teaching of egressed students from the extension projects of AIDS, education and citizenship Program. Method: quantitative cross-sectional study. The participating population of the study was 43 egressed students from the extension project, linked to the nursing course of a Federal

\footnotetext{
${ }^{1}$ Enfermeira, Mestranda do Programa de Pós-Graduação em Enfermagem, Universidade Federal de Santa Maria. Santa Maria, Rio Grande do Sul, Brasil. E-mail: taisa_freitas@hotmail.com

2 Enfermeira, Doutora em Enfermagem, Professora Adjunta do Departamento de Enfermagem, Universidade Federal de Santa Maria, Santa Maria, Rio Grande do Sul, Brasil. E-mail: cris_depaula1@hotmail.com

3 Enfermeira, Doutoranda do Programa de Pós-Graduação em Enfermagem, Universidade Federal de Santa Maria. Santa Maria, Rio Grande do Sul, Brasil. E-mail: bbrunazanon@hotmail.com

${ }^{4}$ Agrônomo, Doutor em Recursos Hídricos e Saneamento Ambiental, Professor Adjunto da Universidade Federal do Rio Grande do Sul, Universidade Federal do Rio Grande do Sul, Porto Alegre, Rio Grande do Sul, Brasil. Email: fernandomeirelles@gmail.com

${ }^{5}$ Enfermeira, Doutora em Enfermagem, Professora Adjunta do Programa de Pós-Graduação em Enfermagem, Universidade Federal de Santa Maria, Santa Maria, Rio Grande do Sul, Brasil. E-mail: weiller2@hotmail.com

${ }^{6}$ Enfermeira, Doutora em Enfermagem, Professora Adjunta do Departamento de Enfermagem, Universidade Federal de Santa Maria, Santa Maria, Rio Grande do Sul, Brasil. E-mail: stelamaris_padoin@hotmail.com
} 


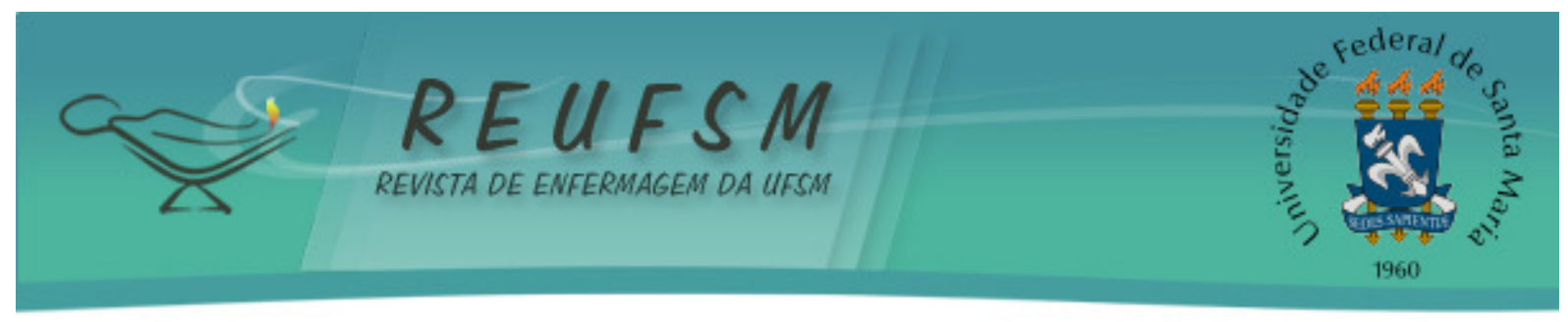

University. Data colletion occured through questionnaires that were sent by email from April to May, 2015 and were analyzed by Prictive Analytics software program. Results: the autonomies obtained after the participation in extension activities wesr emphasized, such as the autonomy on personal development, related to their own learning process, the teamwork, the mutual respect in the work enviroment and the academic improvement, since they had the opportunity to perform activities that are not found in the curriculum. Conclusion: The participation of academics in extension projects increases the responsibility to contribute decisively to social, individual and collective changes.

Descriptors: Educational measurement; Staff development; Teaching; Students, nursing.

RESUMEN: Objetivo: analizar las contribuciones de la extensión en la formación de egresos del proyecto de extensión del programa SIDA, la educación y la ciudadanía. Método: estudio transversal cuantitativo. Los participantes fueron de 43 egresos de proyectos de extensión vinculados al Curso de Enfermería de una Universidad Federal. La recolección de datos fue desarrollada en abril-mayo de 2015, el cuestionario fue enviado por correo electrónico. Los datos fueron analizados por el programa Predictive Analytics Software. Resultados: se destacó la autonomía adquirida después de la participación en las actividades extensionistas, tanto en el desarrollo personal, relacionado con el aprendizaje, trabajo en equipo y respeto al otro, cuanto en el desarrollo académico, en que tuvieron la oportunidad de realizar actividades que no son encontradas en el plan de estudios. Conclusión: La participación de los académicos en proyectos de extensión favorece la responsabilidad de ayudar decisivamente al cambio social, individual y colectivo.

Descriptores: Evaluación educacional; Desarrollo de personal; Enseñanza; Estudiantes de enfermería.

\section{INTRODUÇÃO}

A extensão universitária é um processo educativo, científico e cultural que busca a articulação entre ensino e pesquisa. É compreendida como uma construção de saberes compartilhados, em via de mão dupla, entre acadêmicos e a comunidade. Tem-se como consequência a produção de conhecimento, por meio da vivência com a realidade brasileira e regional. Assim, a Universidade retorna para a comunidade o aprendizado que foi submetido à reflexão teórica. ${ }^{1}$

A política extensionista da Universidade Federal de Santa Maria (UFSM) dispõe que as ações de extensão devem estar voltadas à qualificação do desenvolvimento humano e ao enfrentamento resolutivo de problemáticas da realidade. Além disso, também incentiva a permanente interação pró-ativa da Universidade com a sociedade atendendo às demandas expressas oriundas da comunidade. ${ }^{2}$

Em consonância com a política, são realizadas atividades extensionistas ligadas ao Programa AIDS, educação e cidadania. Neste programa participa uma equipe multiprofissional (enfermeiros, nutricionistas e assistentes sociais); docentes e acadêmicos da UFSM e de outras instituições, públicas e privadas; profissionais de assistência do Hospital Universitário de Santa Maria (HUSM) e servidores técnico-administrativos.

O programa se insere na área do conhecimento das Ciências da Saúde, nas áreas temáticas da saúde e educação e na linha de extensão de saúde humana. As ações de extensão estão vinculadas ao Grupo de Pesquisa Cuidado à Saúde das Pessoas, Famílias e Sociedade (GPPEFAS), do Departamento de Enfermagem da UFSM.

As atividades extensionistas têm como cenário o Ambulatório de Doenças Infecciosas Pediátricas do HUSM, onde são realizados diferentes grupos de apoio a familiares/cuidadores e adolescentes que convivem com HIV, além de atividades lúdicas em uma brinquedoteca implantada no ambulatório para atender crianças portadoras de HIV, que estão em 


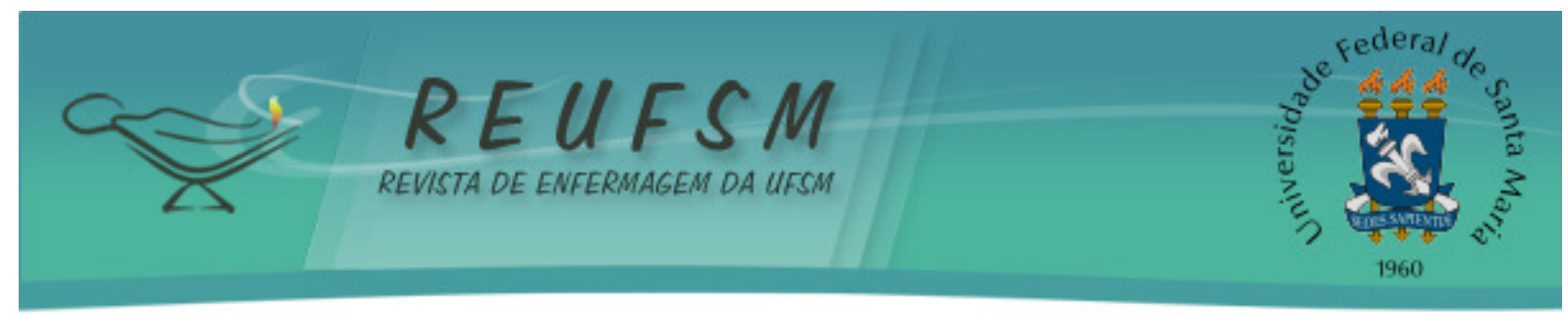

acompanhamento no serviço. Estas atividades de extensão surgiram a partir da necessidade do serviço e atuam como estratégia de resposta às mudanças na epidemia do HIV/AIDS.

Além disso, as atividades propõe a articulação do ensino, pesquisa e extensão na UFSM, buscando interação dialógica, interdisciplinaridade e indissociabilidade. Tais atividades proporcionam, também, a formação de acadêmicos, a qualificação de docentes e profissionais da saúde e, principalmente, a assistência às pessoas que vivem com $\mathrm{HIV}^{3}$

A estratégia de relacionamento e educação por meio de grupos é uma possibilidade dos familiares/cuidadores e adolescentes compartilharem suas experiências e vivências, aliviando os sentimentos de solidão e isolamento social. ${ }^{4}$ Embora a atividade grupal não seja uma prática comum nos serviços de saúde, pode ser eficiente para atender integralmente os usuários, facilitando a comunicação entre os participantes e a equipe de saúde e suprindo as suas necessidades de informação. ${ }^{5}$

É importante reconhecer a estratégia grupal como um espaço para realização de educação em saúde, que não deve ser entendida somente como transmissão de conteúdo, mas também como a adoção de práticas educativas que busquem a autonomia dos sujeitos na condução de sua vida. Esta estratégia ocasiona uma combinação de oportunidades: produção coletiva de conhecimento, oportunizando a autonomia do paciente para avaliar, escolher e decidir suas atitudes, o que corrobora para a manutenção e promoção da sua saúde. ${ }^{6}$

Sendo assim, esta investigação teve como questão de estudo: quais as contribuições das ações de extensão na formação de acadêmicos do curso de enfermagem da UFSM? O objetivo foi analisar as contribuições das ações extensionistas na formação de egressos dos projetos de extensão do Programa AIDS, educação e cidadania.

Justifica-se a presente pesquisa pela necessidade de avaliar as atividades de extensão realizadas pelo Programa AIDS, educação e cidadania, que acontecem há quase duas décadas. Deste modo, pretende-se valorá-la, repetir as ações programadas, inserir estas ações de extensão na Universidade e justificar os investimentos de recursos físicos, financeiros e humanos. Além disso, fortalecer a participação dos integrantes, da comunidade externa e analisar a contribuição de atividades de extensão na formação de acadêmicos de enfermagem. ${ }^{1}$

\section{MÉTODO}

Tratou-se de uma pesquisa com delineamento transversal e abordagem quantitativa. Os participantes do estudo foram egressos do Programa AIDS, educação e cidadania, vinculado ao GP-PEFAS do Departamento de Enfermagem da UFSM. As atividades de extensão foram desenvolvidas no Ambulatório de Doenças Infecciosas Pediátricas do HUSM. O HUSM foi fundado no ano 1970 sendo de um hospital público e de referência para atendimento de crianças, adolescentes, adultos e gestantes que vivem com HIV. Está localizado na região centrooeste do Rio Grande do Sul, fazendo parte da $4^{a}$ Coordenadoria Regional de Saúde. Este hospital é um órgão integrante da UFSM e tem suas ações voltadas para ensino, pesquisa e assistência em saúde. O Ambulatório conta com o Serviço de Infectologia, que é referência no tratamento das crianças e adolescentes que vivem com HIV.

Os critérios de inclusão foram: egressos do curso de graduação e/ou pós-graduação em Enfermagem, participantes do referido programa e bolsistas ou voluntários das atividades de extensão. O critério de exclusão foi ter menos de um semestre de participação nas atividades de extensão, por acreditar que é o tempo mínimo necessário para vivenciar as diversas atividades do programa. Ao longo dos anos, de acordo com os registros do GP-PEFAS, a população foi de 43 extensionistas.

Para a coleta de dados foi elaborado um questionário semiestruturado autoaplicável, para analisar a contribuição das ações extensionistas na formação dos 


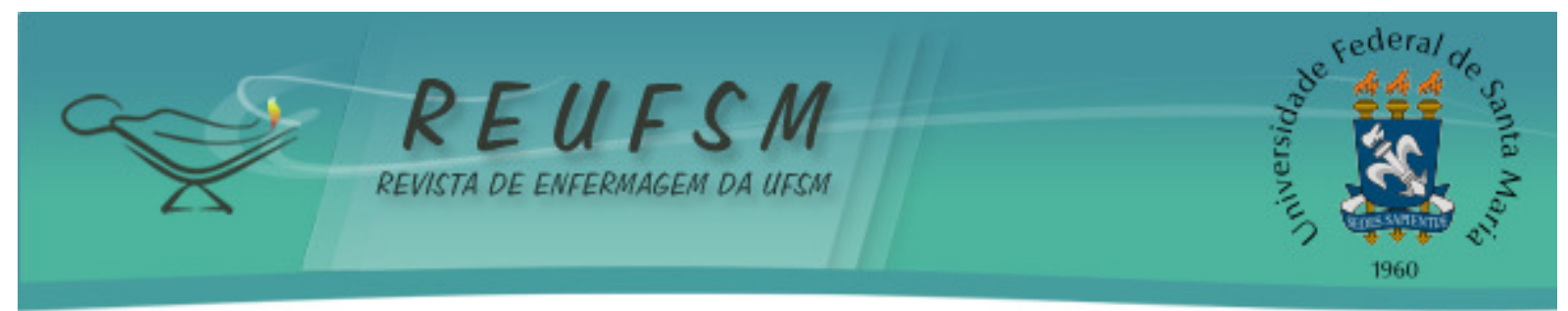

egressos. A primeira versão deste questionário foi submetida à crítica de dois experts: um na temática de AIDS e outro na avaliação da extensão. Todas as contribuições foram acatadas.

Mediante a aprovação do Comitê de Ética em Pesquisa da UFSM, o questionário foi utilizado em teste-piloto. Sem necessidade de adequações, a versão aplicada nesta pesquisa foi composta por 30 questões, multiopcionais e dissertativas. As multiopcionais foram: caracterização (sexo, idade, tipo de vínculo com o Programa, período de vínculo, atuação profissional, escolaridade), participação na extensão (quando e quanto tempo participou) e concepção da extensão (conceito e papel da extensão). As dissertativas foram: pré-requisitos para participar da extensão (momento indicado de inserção na extensão, recomendações de desempenho para o extensionista e coordenador), avaliação de processo (instrumentalização, suporte e oportunidades) e de produto (relação ensino/pesquisa/extensão, contribuição para o desenvolvimento pessoal e acadêmico, conhecimentos e habilidades adquiridas).

O questionário foi disponibilizado online, com o recurso Form Google Docs®. 0 contato com os egressos foi por meio de uma lista disponibilizada pelo GP-PEFAS.

Foram estabelecidas três tentativas de contato por diferentes estratégias. A primeira por correspondência eletrônica (e-mail), com o link do questionário, obtendo a resposta de seis participantes. A segunda estratégia foi por meio de contato por rede social, quando se obteve 0 retorno de 21 participantes. Por fim, foi feito contato telefônico, quando se alcançou resposta de 13 participantes, totalizando 40 respondentes. Houve uma recusa e duas perdas, uma devido a não obtenção de contato eletrônico ou telefônico e a outra por não obtenção de resposta do instrumento. O período de coleta foi abril a maio de 2015.

Para a realização desta pesquisa, os aspectos éticos foram respeitados. Em todas as estratégias, foi informado aos egressos o compromisso de sigilo dos dados pessoais, baseado nos princípios fundamentais da autonomia, beneficência, não maleficência, justiça e equidade.

A coleta de dados, pela internet, possui vantagens: controlar o tempo, diminuir a discrepância de resultados gerada por pesquisadores diferentes, minimizar erros em codificação, e desconhecer o entrevistado. ${ }^{7}$

Por se tratar de uma pesquisa por e-mail, não estava isenta de falhas técnicas oriundas dessa modalidade de coleta de dados (erro de servidor da internet, problemas de sistema, indisponibilidade provisória das páginas). Os dados oriundos das questões multiopcionais foram digitados em planilha Excel e analisados pelo programa Predictive Analytics Software (PASW). As questões dissertativas foram analisadas de forma descritiva.

Os materiais produzidos pela coleta de dados compuseram um banco de dados, arquivado e mantido sob a responsabilidade da orientadora da pesquisa, no laboratório de pesquisa GP-PEFAS no campus universitário. 0 projeto foi aprovado pelo Comitê de Ética em Pesquisa da UFSM, sob protocolo 39967614.8.0000.5346, em 14 de Janeiro de 2015.

\section{RESULTADOS}

A Tabela 1 apresenta a caracterização dos participantes, de acordo com as variáveis: sexo, idade, vínculo com o programa na época em que participou da extensão, área de atuação e escolaridade. 


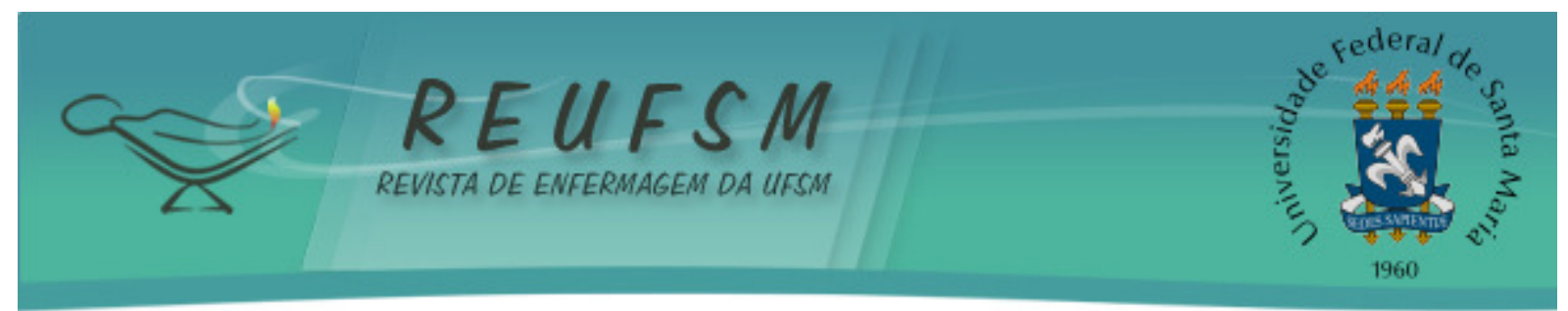

Tabela1 - Caracterização dos participantes do estudo - Brasil - 2015.

\begin{tabular}{lr}
\hline \multicolumn{1}{c}{ Variáveis } & N \\
\hline Sexo & \\
Masculino & 6 \\
Feminino & 34 \\
Idade & \\
$23-28$ & 14 \\
$29-34$ & 15 \\
$35-40$ & 4 \\
$41-46$ & 7 \\
Vinculo com o Programa & \\
Bolsista & 22 \\
Voluntário & 18 \\
Atuação & \\
Assistência & \\
Ensino & 18 \\
Escolaridade & 22 \\
Graduação & \\
Especialização & 8 \\
Mestrado & 11 \\
Doutorado & 16 \\
\hline & 5 \\
\hline
\end{tabular}

As respostas relativas à participação nas atividades de extensão mostraram que 18 extensionistas permaneceram por até dois anos, 15 entre dois e quatro anos, e sete por mais de quatro anos. Sobre qual momento participaram das atividades de extensão: 28 extensionistas durante a graduação, seis na pós-graduação, e seis em ambos.

Sobre a concepção de extensão, questionados em como a definiam na época em que participavam das atividades do Programa: 34 extensionistas responderam instrumento de articulação entre universidade e sociedade, 32 produção de conhecimento, 28 transformação social, 24 articulação da pesquisa, 22 articulação do ensino, 18 cumprimento da missão social da universidade, 18 promoção da interdisciplinaridade, nove transferência de conhecimento e seis prestação de serviço.

Sobre o que acreditavam ser o papel da extensão na universidade pública: 35 extensionistas responderam contribuição da universidade para sociedade, 28 contribuição da universidade para os acadêmicos, 23 área imprescindível em todo curso e 15 obrigação de toda universidade realizar extensão.

Referente aos pré-requisitos, foram questionados sobre o melhor momento para iniciar a participação nas atividades de extensão: 25 extensionistas responderam que não havia um momento indicado para o início e 15 que havia momento indicado. Dentre os que responderam haver melhor momento, todos apontaram que deveria ser no início do curso de graduação.

Sobre a avaliação de processo, procurou-se saber se conheciam a Política de Extensão da UFSM: 25 extensionistas responderam que não conheciam a política de extensão da Universidade e 15 que a conheciam. Na pergunta em que se refere como foram instrumentalizados para iniciar as atividades de extensão: 32 extensionistas responderam que foi a partir da própria vivência na extensão, 27 por meio de grupo de estudos, 21 realizando busca bibliográfica indicada pelo coordenador de extensão, 19 lendo material indicado pelo coordenador de extensão e 14 por meio de busca bibliográfica desenvolvida por conta própria.

Os extensionistas também foram questionados sobre o apoio técnico-logístico que receberam, perante as dificuldades, relacionadas ao período em que participaram das atividades de extensão: 37 extensionistas responderam que receberam apoio do coordenador, 29 de outros bolsistas e/ou voluntários, 11 de outros docentes, oito de familiares dos pacientes e seis receberam apoio dos próprios pacientes. 


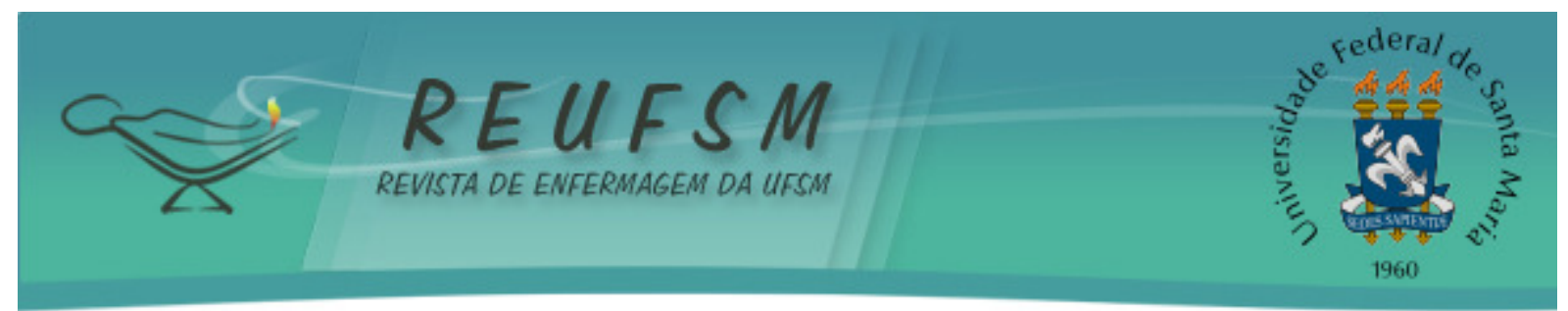

Quanto às oportunidades que os extensionistas tiveram durante a participação nas atividades de extensão: 28 responderam que elaboraram relatório anual das atividades de extensão, 26 participaram da autoria de projetos para continuidade das atividades, 23 registraram as ações no livro ata do Programa, 21 construíram plano de atividades do bolsista de extensão e 15 responderam edital interno da universidade para bolsa de extensão.

Ainda, como oportunidades: 36 extensionistas responderam que escreveram trabalho para eventos como autor ou coautor, 28 apresentaram trabalho em evento como relator, 26 participaram de algum evento de extensão e 22 compartilharam as atividades realizadas durante as reuniões do grupo de pesquisa.

Sobre as atividades desenvolvidas pelos extensionistas de maneira concomitante às atividades de extensão: 36 responderam que participaram de atividades de promoção da saúde, 33 em coleta de dados de pesquisa, 32 das reuniões do grupo de pesquisa, 27 em estudos de revisão e 24 no grupo de estudos.

A avaliação de produto contemplou a relação ensino/pesquisa/extensão, contribuição para o desenvolvimento pessoal e acadêmico, conhecimentos e habilidades adquiridas. Para 38 participantes a participação nos projetos possibilitou conhecer a relação ensino/pesquisa/extensão.

Em relação à contribuição para o desenvolvimento pessoal adquirido durante a participação nas atividades: 39 responderam trabalhar em equipe, 30 capacidade de buscar soluções, 30 respeito ao outro, 28 adquirir autonomia, 27 ser mais criativo, 26 ter mais iniciativa, 25 ter mais segurança, 19 ser menos tímido e conseguir falar em público.

Sobre a contribuição para o seu desenvolvimento acadêmico: 38 realizaram atividades que não são encontradas na grade curricular do curso, 33 desenvolveram projeto de extensão, 31 foram autor/coautor de publicação, 27 desenvolveram atividades de ensino e 25 desenvolveram pesquisa.

Durante a análise dos resultados emergiu o interesse em conhecer quantos dos participantes que marcaram a opção “a extensão universitária é uma contribuição da universidade para sociedade" conheciam a Política de Extensão da UFSM. Dentre os extensionistas que marcaram esta opção, 22 não conheciam a política de extensão e 13 a conheciam. Sendo que cinco pessoas não marcaram esta alternativa.

Analisaram-se, também, as respostas referentes ao "papel da extensão na universidade", relacionando-as com o conhecimento dos extensionistas sobre a Política de Extensão da Universidade. Dentre os 40 participantes, 21 que não conheciam a Política de Extensão também não a definiram como transferência de conhecimento. Entre os participantes que conheciam a Política de Extensão, 11 a definiram como transferência de conhecimento.

Tabela 2 - Demonstrativo da relação entre as respostas: "conhecimento sobre a Política de Extensão da Universidade" e o "papel da extensão na universidade"- Brasil - 2015.

\begin{tabular}{|c|c|c|c|c|c|}
\hline & & \multicolumn{4}{|c|}{ Conhecimento sobre a Política de Extensão } \\
\hline & & \multirow{2}{*}{$\begin{array}{c}\text { Não } \\
n\end{array}$} & \multicolumn{3}{|c|}{ Sim } \\
\hline & & & $\%$ & $\mathbf{N}$ & $\%$ \\
\hline \multirow[t]{2}{*}{ Transferência de conhecimento } & Não & 21 & 52,50 & 1 & 27,50 \\
\hline & Sim & 3 & 7,50 & 5 & 12,50 \\
\hline \multirow[t]{2}{*}{ Produção de conhecimento } & Não & 5 & 12,50 & 3 & 7,50 \\
\hline & Sim & 19 & 47,50 & 13 & 32,50 \\
\hline \multirow[t]{2}{*}{ Transformação social } & Não & 10 & 25,00 & 14 & 35,00 \\
\hline & Sim & 14 & 35,00 & 2 & 5,00 \\
\hline \multirow{2}{*}{$\begin{array}{l}\text { Articulação entre universidade e } \\
\text { sociedade }\end{array}$} & Não & 4 & 10,00 & 2 & 5,00 \\
\hline & Sim & 20 & 50,00 & 14 & 35,00 \\
\hline
\end{tabular}




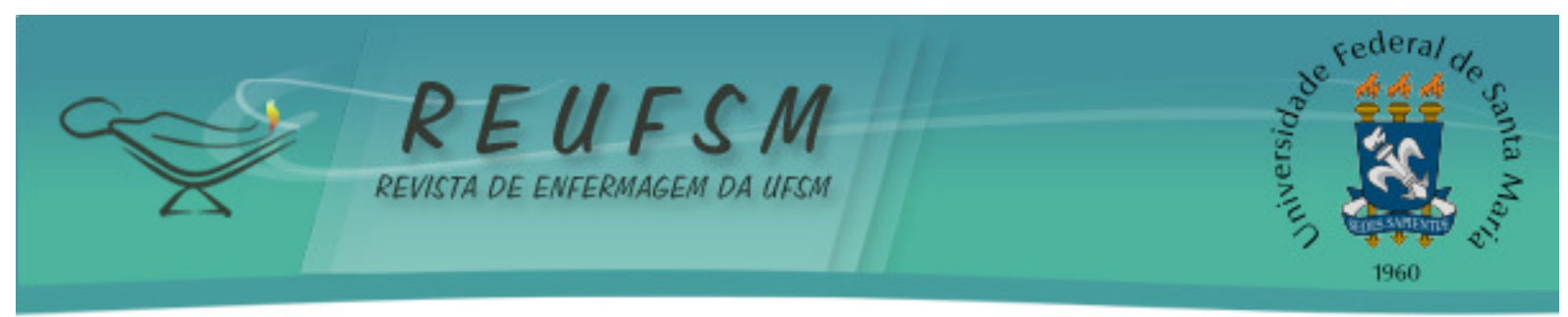

Entre os participantes que conheciam a Política de Extensão da UFSM, 14 definiram o seu papel como transformação social e 13 como produção de conhecimento. Entre os que não a conheciam, 14 a definiram como transformação social e 19 como produção de conhecimento. Dos extensionistas que marcaram a opção "a extensão é uma articulação entre a universidade e sociedade”, 20 não conheciam a política e 14 a conheciam.

Sobre a fonte de informação que os extensionistas buscaram para definir a extensão universitária: dos 24 que não conheciam a Política de Extensão da UFSM, 21 responderam que buscaram as vivências na própria atividade, dois nas disciplinas do curso de graduação em Enfermagem, e um em material bibliográfico. Dos 16 participantes que conheciam a política, 12 responderam que buscaram as vivências na própria atividade de extensão, dois nas disciplinas do curso de graduação em Enfermagem, um na própria Política de Extensão da UFSM e um em material bibliográfico.

Entre as facilidades que encontraram durante a participação nas atividades, destacaramse a relação interpessoal e a construção do conhecimento compartilhado. Entre as principais dificuldades vivenciadas, os participantes relataram falar em público, pouco reconhecimento do serviço em que os projetos estão inseridos e dificuldade em administrar o tempo entre as responsabilidades da graduação e da extensão.

Sobre os conhecimentos teóricos adquiridos pelos extensionistas durante a participação nas atividades, destacou-se o aprendizado temático acerca do HIV, e metodológico, devido à participação, concomitante, nos grupos de pesquisa. Os participantes disseram aplicar os conhecimentos adquiridos durante sua rotina atual de trabalho tanto no ensino como na assistência. A respeito das habilidades práticas adquiridas, houve consenso sobre a articulação entre teoria e prática, sendo que estas habilidades são aplicadas atualmente em suas práticas de assistência, docência e pesquisa.

Os extensionistas do Programa AIDS, educação e cidadania, apontaram o comprometimento e o conhecimento sobre a temática como fatores fundamentais para o desempenho do acadêmico nas atividades de extensão. Sugeriram como recomendações para os coordenadores do programa: a instrumentalização permanente, 0 apoio às dificuldades encontradas na extensão e o incentivo à participação nos projetos de extensão da universidade.

\section{DISCUSSÃO}

Apesar de 25 participantes não conhecerem a Política de Extensão da Universidade, na época em que participaram dos projetos, e terem sidos instrumentalizados a partir da própria vivência nas atividades, eles a definiram como um instrumento de articulação entre a universidade e a sociedade, de produção de conhecimento e de transformação social. Essa definição está em consonância com a Política de Extensão da UFSM, que possui como objetivo articular ações de interesse comum entre a universidade e a sociedade, buscando atender suas demandas gerais. ${ }^{2}$

Tal política indica que se deve considerar as ações voltadas para o desenvolvimento, produção e preservação cultural e artística e disponibilizar à comunidade conhecimentos científicos, tecnológicos e culturais, infraestrutura material e recursos humanos para a elaboração e implementação das políticas públicas voltadas ao benefício da sociedade. ${ }^{2}$ Percebe-se que os egressos possuem concepção adequada dos objetivos da extensão universitária e o seu papel como contribuição da universidade para a sociedade e da universidade para os acadêmicos.

Para que a extensão seja transformadora é importante que o ensino e a pesquisa interajam com a sociedade, para que a universidade reúna as contribuições, críticas e transformações. É necessário captar este aprendizado para possibilitar a atualização de currículos escolares, pesquisa, práticas de ensino e gestão. ${ }^{1}$ Os resultados mostraram que os 


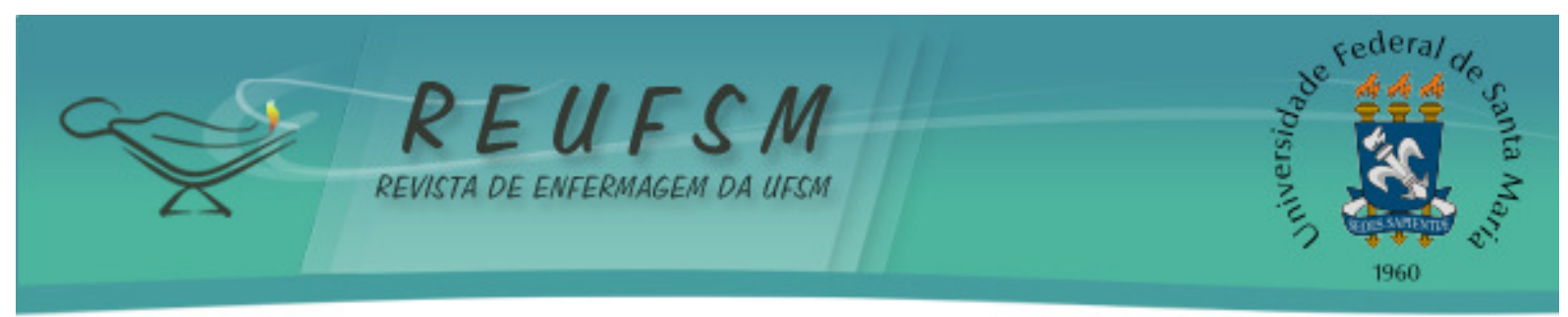

egressos tiveram oportunidade de participar de atividades como: elaborar trabalho para eventos, ser autor de projetos para dar continuidade às ações planejadas e escrever relatórios anuais das tarefas desenvolvidas, concomitantemente, com as atividades de extensão. Eles também atuaram em coleta de dados, estudo de revisão e participação em grupo de pesquisa, demonstrando que conseguiram, durante a participação no projeto, verificar a relação entre ensino, pesquisa e extensão.

A Lei de Diretrizes e Bases da Educação Nacional no Brasil (LDB), que se refere à educação superior no país, enfatiza a importância de estimular os acadêmicos na vivência e no conhecimento do mundo atual, por intermédio da prestação de serviços às comunidades, estabelecendo reciprocidade. Prevê, também, a promoção da extensão integrada à população, buscando a construção de benefícios, tanto para os acadêmicos como para a comunidade, resultado da transformação cultural da pesquisa científica e das tecnologias disponibilizadas pela instituição. ${ }^{8}$

Sendo assim, as atividades de extensão promoveram aproximação à prática profissional, sendo este um campo fértil para a construção de conhecimento. A formação apreendida em espaços diferentes, a exemplo da comunidade, contribui para a compreensão de um ser socialmente responsável e capaz de refletir acerca das vivências cotidianas, construindo a sua identidade, tanto pessoal quanto profissional, sustentada na busca contínua do saber. ${ }^{9}$

Os egressos acreditam que a participação nas atividades de extensão contribuiu para o seu desenvolvimento pessoal, auxiliando no aprendizado para o trabalho em equipe. Desenvolveram capacidade de buscar soluções, respeito ao outro e adquiriram autonomia, sendo criativos e tendo mais iniciativa. Contribuiu, ainda, para o seu desenvolvimento acadêmico, pois nos projetos realizavam atividades que não são encontradas na grade curricular.

É necessário ressaltar que as Diretrizes Curriculares Nacionais do Curso de Graduação em Enfermagem preveem que 0 projeto pedagógico do curso deve ofertar atividades complementares e mecanismos de aproveitamento do conhecimento. Isso deve ocorrer por meio de estudos e práticas independentes, como: monitorias e estágios, programas de iniciação científica e extensão, estudos complementares e cursos realizados em outras áreas da saúde. ${ }^{10}$

Assim, é preciso buscar a formação integral e adequada do acadêmico, por meio da articulação entre o ensino, a pesquisa e a extensão/assistência, garantindo um ensino crítico, reflexivo e criativo. Estimular, também, a realização de experimentos e/ou de projetos de pesquisa, socializando o conhecimento produzido, considerando a evolução epistemológica dos modelos explicativos do processo saúde-doença. ${ }^{10}$

A extensão universitária permite ao acadêmico uma compreensão da realidade regional e nacional da sociedade. 0 método de mediação de conflitos utilizado em grupos exige um repensar sobre o conflito, reconhecendo-o como algo inerente à condição humana. ${ }^{11}$

Na mediação pautada no diálogo se considera a participação voluntária das pessoas. É uma técnica em que o mediador facilita a comunicação entre os participantes, tentando resgatar a autonomia e os interesses, fazendo com que os participantes aprendam uns com os outros e que ele mesmo aprenda com o grupo. Do acadêmico que atua como moderador nos projetos de extensão é exigida constante preparação e troca de conhecimento. ${ }^{12}$

Os egressos atribuíram a própria vivência nos projetos de extensão como sua principal fonte de informação para a definição de seu significado, sendo que 25 participantes não conheciam a Política de Extensão da UFSM apesar de a terem definido de forma correta.

Ao integrar um projeto de extensão, o acadêmico se relaciona direta e prematuramente com a realidade, vivência indispensável para a sua formação, o que the permite colocar em prática os conhecimentos adquiridos em sala de aula e durante a vida. Inevitavelmente, devem surgir inquietações decorrentes da desigualdade e dificuldades do serviço, contribuindo para o desenvolvimento ético, além de aplicar conhecimento teórico-prático aprendido durante a graduação. ${ }^{12}$ 


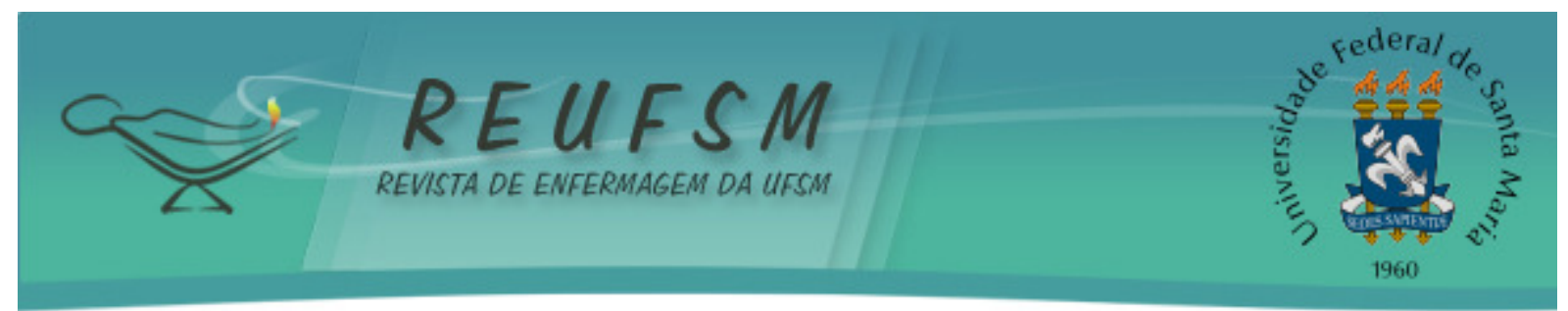

Nesse contexto, o processo de formação do profissional de saúde é imprescindível para a transformação das práticas profissionais atuais, de modo a realizar as intervenções de acordo com a realidade sanitária da população em que está inserido. É necessário buscar uma proposta de rede articulada entre instituições de ensino, serviços de saúde, comunidade e gestão do Sistema Único de Saúde (SUS). ${ }^{9}$

A formação do acadêmico não deve ser pautada somente na transmissão de conhecimento, mas na problematização e na transformação da realidade local. Sendo que é indispensável integrar docentes, acadêmicos, usuários do serviço, gestores, funcionários e equipe multiprofissional, com o intuito de fortalecer os princípios do SUS. ${ }^{9}$

A visibilidade e o reconhecimento da atuação dos acadêmicos, em redes públicas de saúde, ganhou força com os projetos de extensão universitária. Estas atividades, incluindo as de educação em saúde, devem ser valorizadas, pois oportunizam formação adequada, integrando estratégias que buscam a capacitação de futuros trabalhadores para o SUS. ${ }^{9}$ Além disso, essa integração viabiliza estratégias para o ensino, desenvolve potencialidades no acadêmico para enfatizar a compreensão dos conteúdos no processo de aprendizagem e fortalece a prática pedagógica. ${ }^{12}$

\section{CONCLUSÃO}

A participação dos acadêmicos em projetos de extensão favorece a responsabilidade de contribuir de maneira decisiva para a transformação social. Além disso, estas atividades proporcionam um espaço privilegiado para a criação de rede de apoio, reflexão e conscientização do processo saúde-doença, e intervenção, bem como um ambiente de ensinoaprendizagem, vínculo afetivo pessoal/profissional e organização social.

A vivência nas atividades de extensão contribuiu para a formação de acadêmicos, sujeitos sociais, individuais ou coletivos, transformados. Eles desenvolveram conhecimento pelo contato diário com a temática trabalhada, realizando associação teórico-prática; troca de experiência entre os usuários, acadêmicos, docentes e equipe multiprofissional; ampliando sua visão crítica sobre a educação em saúde e a realidade do SUS.

As limitações do desenvolvimento da pesquisa incluíram escassez de estudos que auxiliassem na discussão dos achados resultados encontrados; colaboração dos participantes em aderir à pesquisa, por se tratar de um questionário eletrônico, enviado por e-mail; e carência de materiais que abordassem técnicas de avaliação de ações de extensão.

Neste sentido, faz-se necessária a realização de novas pesquisas, com enfoque na avaliação das ações de extensão. Indica-se a possibilidade de aprimoramento e validação do instrumento utilizado nesta pesquisa, buscando auxiliar e contribuir na avaliação de projetos de extensão em todas as áreas.

\section{REFERÊNCIAS}

1. Nogueira MDP, Mendes SR, Meirelles FSC, Sousa Al, Cunha EP, Guimarães MB, et al. Avaliação da Extensão Universitária: práticas e discussões da Comissão Permanente de Avaliação da Extensão. Belo Horizonte: PROEX/UFMG; 2013.

2. Brasil. Ministério da Educação. Universidade Federal de Santa Maria. Pró-Reitoria de Extensão. Política de Extensão da UFSM [Internet]. 2008 [acesso em 2015 jun 9]. Disponível em: http://jararaca.ufsm.br/websites/prex/download/Politica/Politica.pdf.

3. Paula CC, Padoin SMM, Langendorf TF, Mutti CF, Hoffmann IC, Valadão MC. Acompanhamento ambulatorial de crianças que tem HIV: cuidado centrado na criança e na família. Cienc Cuid Saúde. 2012;11(1):196-201. 


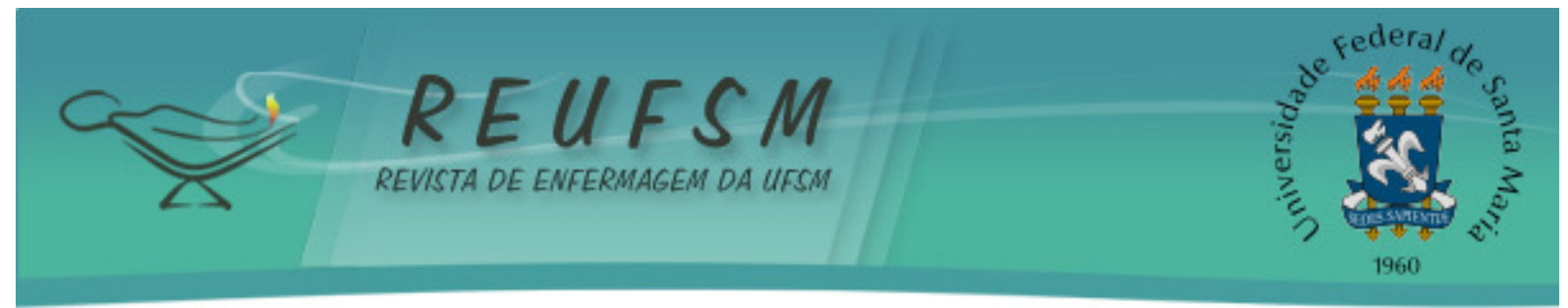

4. Dahdah DF, Carvalho AMP, Delsim JC, Gomes BR, Miguel VS. Grupo de familiares acompanhantes de pacientes hospitalizados: estratégia de intervenção da Terapia Ocupacional em um hospital geral. Cad Ter Ocup UFSCar. 2013;21(2):399-404.

5. Santos LF, Oliveira LMAC, Munari DB, Peixoto MKAV, Silva CC, Ferreira ACM, et al. Grupo de suporte como estratégia para assistência de enfermagem à família de recém-nascidos hospitalizados. Rev Eletrônica Enferm. 2012;14(1):42-9.

6. Yuahasi KK. Construção da afetividade no exercício do convívio grupal. Conscientia. 2014;18(3):289-96.

7. Wachelke J, Natividade J, Andrade A, Wolter R, Camargo B. Caracterização e avaliação de um procedimento de coleta de dados online. Aval Psicol. 2014;13(1):143-6.

8. Brasil. Ministério da Educação. Lei $n^{\circ}$ 9.394, de 20 de dezembro de 1996. Estabelece as diretrizes e bases da educação nacional [Internet]. 2015 [acesso em 2016 mar 30]. Disponível em: http://www.planalto.gov.br/ccivil_03/leis/L9394.htm.

9. Biscarde DGS, Santos MP, Silva LB. Formação em saúde, extensão universitária e Sistema Único de Saúde (SUS): conexões necessárias entre conhecimento e intervenção centradas na realidade e repercussões no processo formativo. Interface Comum Saúde Educ Enferm. 2014;18(48):177-86.

10. Brasil. Ministério da Educação. Conselho Nacional de Educação. Resolução CNE/CES $n^{\circ} 3$, de 7 de novembro de 2001. Institui Diretrizes Curriculares Nacionais do Curso de Graduação em Enfermagem [Internet]. Brasília; 2001 [acesso em 2015 jun 9]. Disponível em: http://portal.mec.gov.br/cne/arquivos/pdf/CES03.pdf.

11. Oliveira LMAC, Medeiros M, Barbosa MA, Siqueira KM, Oliveira PMC, Munari DB. Grupo de suporte como estratégia para acolhimento de familiares de pacientes em Unidade de Terapia Intensiva. Rev Esc Enferm USP. 2010;44(2):429-36.

12. Santos MP. A extensão universitária como "laboratório" de ensino, pesquisa científica e aprendizagem profissional: um estudo de caso com estudantes do curso de licenciatura em pedagogia de uma faculdade particular do estado do Paraná. Extensio: Rev Eletrônica de Extensão Enferm. 2014;11(18):36-52.

Data de recebimento: 14/10/2015

Data de aceite: 14/06/2016

Contato do autor responsável: Cristiane Cardoso de Paula

Endereço postal: Universidade Federal de Santa Maria, Departamento de Enfermagem. Av. Roraima, $\mathrm{s} / \mathrm{n}^{\circ}$, prédio 26, sala 1.336. Cidade Universitária, Camobi .CEP 97105-900. Santa Maria/RS, Brasil. E-mail: cris_depaula1@hotmail.com 